\title{
Entrepreneurship of Eco-system and Its Transformation, Using the Example of Republic of Egypt
}

\author{
Veronika Silinevicha, Hany Moussa, Kristine Kalinina* \\ Baltic International Academy, Latvia \\ *Corresponding Author: golubkovak@mail.ru
}

Copyright $\bigcirc 2017$ by authors, all rights reserved. Authors agree that this article remains permanently open access under the terms of the Creative Commons Attribution License 4.0 International License

\begin{abstract}
The Egyptian economy is one of the most diversified economies in the Middle East-tourism, agriculture, manufacturing and services sectors all contribute with semi-equal ratios to the gross national product. Due to recent structural reform, the Egyptian economy is achieving high growth rates - and an attractive investment climate has evolved thanks to positive developments in infrastructure, transportation, communication, energy, skilled labor, modern industrial cities, free zones, banking and stock markets.
\end{abstract}

Keywords Eco-system, Economy, GDP Growth, Enterprise

\section{Introduction}

Egypt's current social and political transformation poses historic challenges and opportunities for its economic development and growth. The lack of employment opportunities, particularly for youth under the age of thirty-five has been cited as one of the principal causes of the Egyptian revolution and the country's political unrest, which has taken its toll on the Egyptian economy. With political uncertainty and economic slowdown, there is an ever more urgent need to create jobs for young Egyptians. Unemployment has reached its highest level, particularly among women and youth in Upper Egypt, at $13.4 \%$ in 2013.[1]

Micro, small and medium enterprises (MSMEs) are the backbone of any economy. Nowadays, when governments or international institutions put forward a plan or policy, they show great concern about the role of MSMEs in the economy as they know that these businesses are crucial to economic growth and development. Yet despite the importance of such enterprises for Egypt, obstacles often stand in the way of their development, such as financial and political issues, lack of technology adoption and unskilled workers. Furthermore, MSME owners of these businesses tend to have informal financing - borrowing from relatives, friends and rotating credit associations (Gameia) - instead of formal financing, which requires long and complicated procedures (including registering as an entity).

\section{Depicting Enterprise Ecosystem in Egypt}

The Government of Egypt targeted a growth rate of over $3 \%$ during FY13/14 and intends to pursue a long-term plan to support growth by injecting an incentive package of EGP 30 billion. The incentive package will be used to support public-sector investments and infrastructure projects. The following main macroeconomic indicators of the Egyptian economy are provided to give a perspective of the overall business environment in Egypt.

The second quarter (Q2) of FY13/14 witnessed several political developments towards the fulfillment of the Roadmap, ${ }^{1}$ which positively affected the Egyptian economy. Thanks to financial aids provided by Gulf countries combined with Egypt's active economic plan, Standard and Poor's increased Egypt's sovereign credit rating in November 2013 (for the first time since January 2011) from $\mathrm{CCC}+/ \mathrm{C}$ to $\mathrm{B}-\mathrm{B}$ in the short and long terms and also at the level of local and foreign currencies. That a sovereign credit rating agency observed the remarkable improvement in the Egyptian economic stability is a primary step towards restoring international markets' confidence in the Egyptian economy.

According to the most recent labor force sample survey conducted at the end of Q1 FY14, the unemployment rate stood at $13.4 \%$ compared to $13.2 \%$ at the end of Q1 FY13.

Taking the most recent data available from the General Authority for Investment and Free Zones on newly established companies for June 2014, 800 new companies were established by Egyptian, Arab and foreign private investors, compared to 755 companies set up in June 2013. The daily average of new companies established in June 2014 was 36 . The services sector accounted for the bulk of

1 The Roadmap is for a transfer to civilian power and includes the successful completion of parliamentary elections. 
new establishments, with 344 new companies. The services sector was followed by manufacturing (208 companies), construction and building (128 companies), information and communication technology (46 companies), agriculture (43 companies), tourism (29 companies) and financing services ( 2 companies). During June 2014, female owners established $9 \%$ of new companies, whereas males established $77 \%$ of new companies in the same period. Legal entities accounted for the remaining $14 \%$ of new establishments.
At the level of investment in specific governorates for this June 2014 period, Assuit accounted for the bulk of new establishments, with 19 companies, followed by Sharqia with 12 companies and Cairo with 8 companies. The issued capital for the newly established companies totaled EGP 1403.5 million, with Assuit accounting for the largest share, with an EGP 29.6 million. Suez followed with EGP 23.7 million, and Souhag with EGP 10.6 million.[2]

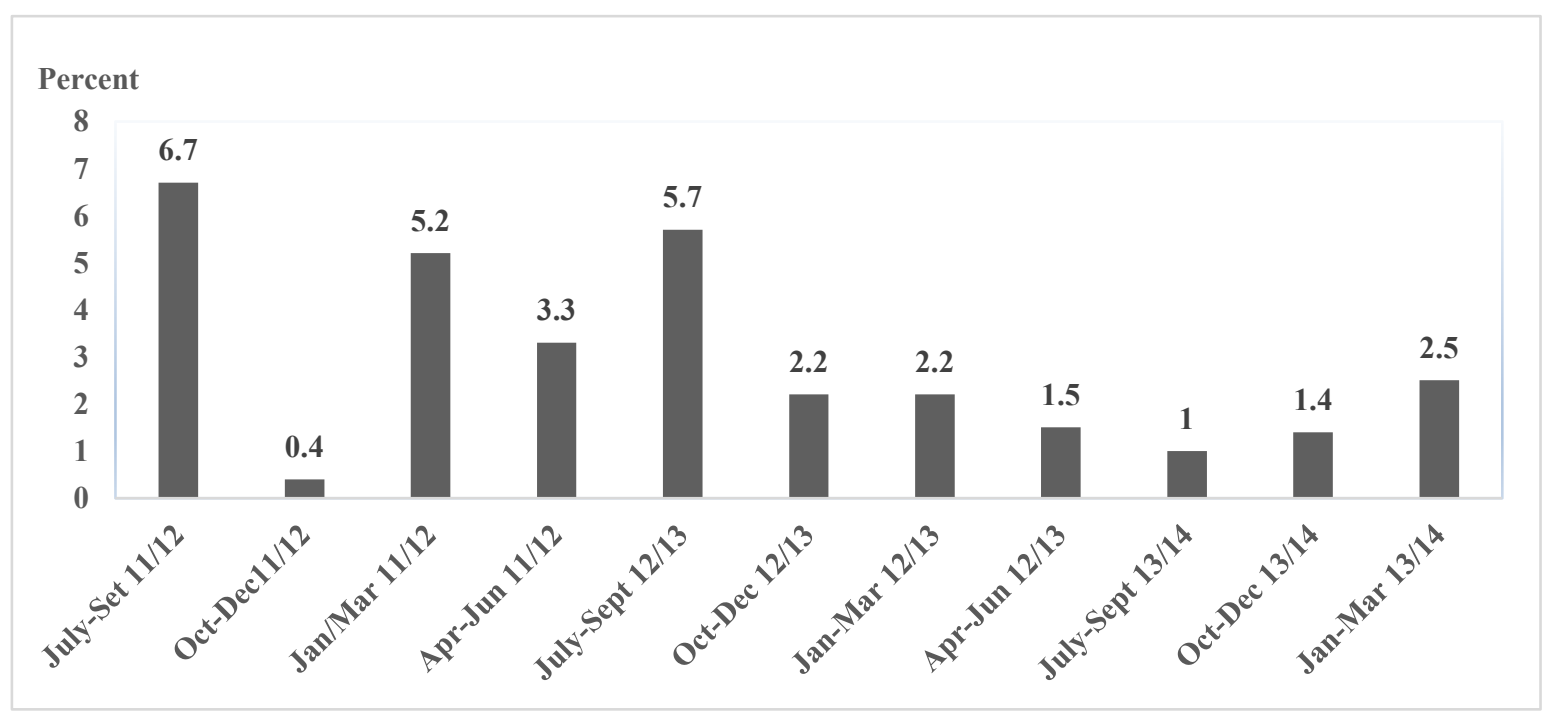

Figure 1. Real GDP growth [2]

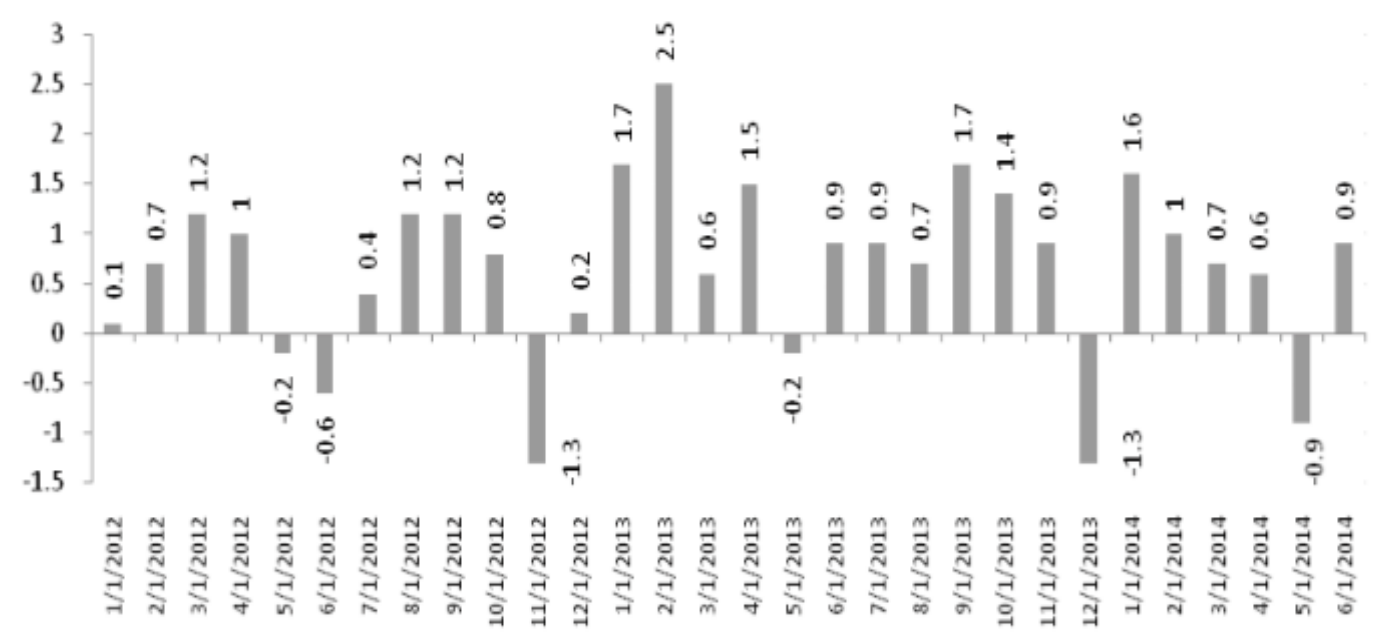

Figure 2. Change in inflation rates in consumer prices [2] 


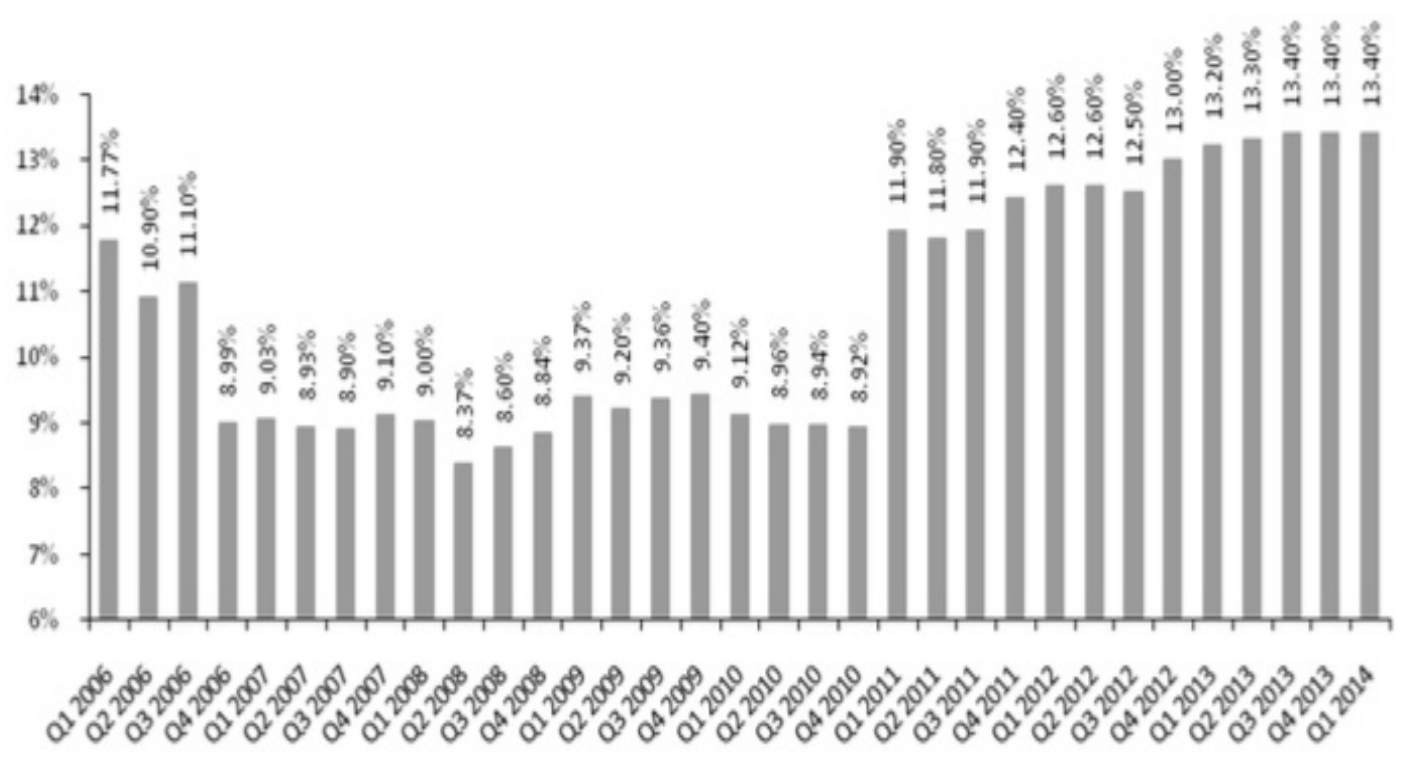

Figure 3. Unemployment Rates [2]

(The information above is for all companies established regardless of their size. ACCELERATE has requested this information from the General Authority for Investments and Free Zones for the SMEs established in FY12/13. Information is expected to be ready by the end of August 2014.)

Over the past few years, Egypt has made strides in recognizing the importance of the SME sector and its significant contribution to economic growth and job creation in Egypt. While there have been efforts to improve the business environment for local entrepreneurs, these efforts have been diluted by a lack of sustained commitment to substantive changes and an unwillingness to risk upsetting the established order.

According to Egypt's Doing Business Report of 2014, the country is still facing structural challenges that impede private-sector activity. With an aggregate ease of doing business ranking of 128 among 189 economies (see figure below), Egypt still has room for much improvement-for example, via clearer and more transparent rules applied more consistently. Such rules would facilitate rather than impede the private sector in Egypt, where the need to encourage entrepreneurship is thus, perhaps even more urgent than in other countries. [3], [4]

Hence, the Government of Egypt should prioritize SME encouragement as part of its short- and long- term strategy for development. For example, the government should allow temporary business licenses (able to be transformed into permanent licenses by the power of law within thirty days) and offer tax exemptions to SMEs for five years from the date of establishment.

In recent years, Egypt has recognized the importance of having a policy framework to support SMEs. Under the terms of a 2004 law, the government has developed a structured policy framework for micro and small enterprises
(MSEs) that is the responsibility of the Social Fund for Development, the main public player and policy coordinator for the micro and small segment of the SME population. In parallel, the Social Fund for Development has recently developed targeted policy tools to help MSEs establish and grow their businesses by providing a range of programs such as business support services, microfinance activities and a network of business incubators. [5]

Egypt has also made considerable improvements in delivering targeted policy to enhance SME innovation through dedicated centers and networks - namely, through the Egypt Technology Transfer and Innovation Centers. The country also performs moderately well in helping to improve these enterprises' operations through startup and growth services provided by the Industrial Modernization Center.

Yet, multifaceted challenges still impede further development of the micro, small and medium enterprise (MSME) sector in Egypt. Among these challenges are the following:

- A policy gap exists regarding SMEs with high-growth potential, a sector where institutions are active, but working in isolation from one another and sometimes ill-equipped to meet the needs of fast these fast-growing enterprises;

- The high number of informal businesses in this sector distorts competition and inhibits the effectiveness of government policies;

- Targeted policy tools appear to favor medium-sized, well-established industrial enterprises over younger, smaller enterprises with high-growth potential operating in the services; and

- Lack of coordination among institutions results in support programs not benefiting MSMEs for which they were designed. [6]

The momentum is building in the region as the Arab 
Spring generates an appetite for reform, providing new opportunities for MSMEs. Egypt's new government is committed to supporting and developing these enterprises by improving their enabling environment and increasing their access to finance. In June 2014, a new portfolio for SMEs was added to the already existing Ministry of Trade and Industry. Nonetheless, the new government still anticipates a long development process since it has yet to address the priorities that have become more pressing after the January 25 and June 30 revolutions - priorities that include opening up further access to private-sector opportunities for income and employment and easing significant constraints on enterprise operations, startup, competitiveness and growth. [7]

\subsection{Recent Developments}

Given the urgent need to create jobs that can absorb the high unemployment rates, in addition to the various challenges posed by global economic development, Egypt has been intent on creating a strong, competitive MSME sector that is able to play a leading role in the development process. It is in this context that this sector's development has become a major focus of attention for the Government of Egypt, donor agencies, private-sector initiatives and nongovernmental organizations (NGOs) since the late 1990s. However, despite its high priority, no coherent policy for MSMEs has been developed.

Although there have been several different governments, private sector and donor players in the market, they faced various constraints such as 1) absence of a clear policy towards MSMEs development to guide and coordinate the various efforts to maximize their benefit; 2) lack of a unified operational definition for the target group; 3) lack of sufficient and adequate information on the sector; and 4) lack of coordination among the various institutional actors. However, some efforts and initiatives undertaken by the Egyptian government-as well as by donors, the private sector and NGOs - to develop the MSME ecosystem have proved promising and successful.

Efforts to support such enterprises in Egypt can be attributed to the following:

- Government Efforts

- Banking-Sector Reform

- Donor Support

- $\quad$ Private-Sector Support [8]

\subsection{Government Efforts to Enhance the Micro, Small and Medium Enterprise Ecosystem}

Creation of a settlement committee for new investment disputes. The Prime Minister, Ibrahim Mehleb, issued a decree to set up a committee to settle investment disputes. The new entity is chaired by the minister of Justice and includes the ministers of Trade and Industry; Local Development; Finance; and Investment and Transitional
Justice. It also includes chair of the General Authority for Investment and Free Zones, chair of the State Council's Advisory Body and secretary general of the Council of Ministers. [9]

Prioritization of investment legislation amendments: According to the Minister of Investment, Ashraf Salman, updating and amending the investment laws top the priorities for the Ministry of Investment since these laws will play a big role in encouraging investments and helping to clear out many obstacles and issues that used to hinder both domestic and foreign investors. Following the meeting of the newly reshuffled council of ministers with President Abdel Fattah Al Sisi, Salman added that his ministry will be giving much attention to attracting foreign investments to enhance the economy, create more jobs and reduce the high unemployment rate.

Simplification of license procedures: All services rendered by the General Authority for Investment and Free Zones are being simplified and streamlined, said its chairman, Hasan Fahmi. He added that the governmental authority also seeks to decentralize through its branches in Alexandria, Assuit, Ismailia and Tenth of Ramadan. More coordination will take place with different license providers so that licenses are issued from the General Authority's One-Stop Shop, Fahmi announced. Coordination is underway with the National Center for Planning State Land Uses to offer lands available for investment via the General Authority, while allocation shall be made by the competent bodies.

Establishment of The General Authority for Investment and Free Zones' new branches in Sohag, Sixth of October and Gamasa .The General Authority for Investment and Free Zones will open three new branches in Sohag, Sixth of October and Gamasa (FY 2014/15) to provide investment services, said the Minister of Trade, Industry and Investment, Monir Fakhri Abdel Nour. The inauguration of these new branches is in line with the Ministry's plan to roll out the one-stop-shop system to bring together into one place providers of licenses and investment zone permits, expand decentralization and help investors. Abdel Nour said that the government seeks to clear out all obstacles to producers and investors and provide necessary support to start up their businesses. He noted that coordination is underway with the Ministry of Housing and the New Urban Communities Authority to design specific and appropriate mechanisms for distributing and allocating industrial lands for investors in the period to come.

Adoption of microfinance laws: The Council of Ministers approved a draft law on microfinance to create new mechanisms of finance for microenterprises, which typically do not have access to traditional finance institutions, said the Minister of Trade, Industry and Investment, Monir Fakhri Abdel Nour. The law primarily seeks to regulate and supervise the microfinance business by ensuring protection for related parties' interests and overseeing finance providers to ensure efficiency, transparency and social justice. The law also seeks to fight poverty. According to the new draft law, a 
special unit will be established within the Egyptian Financial Supervision Authority to oversee microfinance provided by associations and nongovernmental organizations, which will include representatives of relevant ministries and entities, most notably the Social Fund for Development. The unit will fight abuses and illegal activities from this type of finance-associations being an easy and penetrable target-action which requires no substantial financial expertise. [10]

\subsection{Banking-Sector Reforms}

In Egypt, despite banking reforms that had been launched in 2004, the limited ability of MSMEs to easily access suitable and sufficient means of finance has always been considered a major obstacle faced in these enterprises. From a supply point of view, most banks are becoming more risk averse towards SMEs, especially due to a widespread notion that financing these enterprises is risky and that serving them requires high transaction costs that make them less profitable than larger companies.

Thus, the Central Bank of Egypt launched in December 2008 an initiative, as an integral part of Phase II of the Banking-Sector Reform Program (2008-2011), to enhance SMEs' access to finance and banking services. Those reforms led to robust, solid and well-capitalized banks. The number of banks decreased from 57 to 39; assets increased by $88 \%$ to reach EGP 1.1 billion in 2008 - up from EGP 0.57 billion in 2003 -with total deposits increasing by $85 \%$ over the same period; the capital adequacy ratio increased from $12.2 \%$ to reach $15.1 \%$; and total net worth increased by more than $100 \%$ from EGP 32 billion to EGP 75 billion. Yet, despite the significant improvement at the macroeconomic level, there is still a challenge related to the access to finance, especially for SMEs. [11]

Today, just under half of Egypt's banks have activity in SME banking. These include the National Bank of Egypt (the largest one), Banque Misr, AlexBank, Suez Canal Bank, United Bank, HSBC, the Commercial International Bank, and Banque du Caire (the microfinance pioneer). The government had announced prior to 2011 that it would transform a major state-owned bank (Banque du Caire) into a lender to SMEs, but little progress had been made when efforts ceased as of Jan. 25, 2011. There has been progress, however, in registering more microfinance institutions in the credit bureau database. [12]

Despite the Central Bank's push in this sector, incentives for banks to build SME portfolios are still weak (high cost, high risk, lack of innovation in products and services) - only four main banks are engaged in micro-lending in Egypt. Banks extend credit using their own resources or in their capacity as loan managers, either on behalf of donors or, more typically, on behalf of the Social Fund for Development. The National Bank of Egypt has been providing financing for working capital since the late 1980s. The Principal Bank for Development and Agriculture started its rural finance program in 1993. More recent entrants into the sector are Banque du Caire, which started its micro-lending operations in 2001, and Bank Misr, which began micro-lending in September 2003. By virtue of an agreement signed with the Spanish Agency for International Cooperation in 2001, the Commercial International Bank has been managing a microcredit fund that it disburses through the National Bank of Egypt.

Yet the microfinance sector still remains broadly underdeveloped, with SMEs unable to obtain adequate finance and the nonbank financial side of MSME finance being minimal. The Social Fund for Development does more microfinance, but factoring and leasing is still limited - and angel investors are few. In the nonbank financial sector, microfinance institutions are weak and inefficient in supplying credit. The already difficult circumstances facing MSMEs in accessing finance could worsen with the recent economic and political developments. Financial services in Egypt are underutilized by these businesses as only $50 \%$ are dealing with banks. [11]

\subsection{Donors Efforts to Enhance the Micro, Small and Medium Enterprise Ecosystem}

In recent years, the interest among donors in MSME development has increased-an overall positive trend. However, at times, donors are working on parallel initiatives that do not always complement one another. This is particularly true of groups that continue to subsidize financial and nonfinancial services while others are trying to make them more financially sustainable. The following are some, but not all, of the donors' efforts undertaken in the past few years to support and develop MSMEs in Egypt.

World Bank: The World Bank grant for SMEs has three pillars: SME regulatory framework (still no law for microfinance), capacity building of banks and nonbanks, and capacity building of SMEs.

The World Bank's USD \$300 million Enhancing Access to Finance for Micro, Small and Medium Enterprises Project aims to sustainably improve inclusive access to finance for MSMSEs on a commercial basis through a line of credit and apex institutions that on-lend the funding to banks and microfinance nongovernmental organizations. The USD 300 million loan for these enterprises will go through the Social Fund for Development, as they cannot lend directly to SMEs, but through regulated financial institutions. There had been an attempt to work through the Post Office, but changes in management at the Post Office made it impossible to pursue. The World Bank also works with the Alexandria Business Association. However, the World Bank program aiming to support MSMEs is only via loans and technical assistance facilities.

Canadian Aid: The Government of Egypt has also turned to Canada for support in the MSME sector. In 2000, the Small and Medium Enterprise Policy Development Project was created with the support of Canada's International 
Development Research Center and efforts by the Egyptian government to bring about significant policy changes. The project has been successful in developing a more favorable regulatory framework, enacting revisions to the income tax regime, initiating a thorough assessment of the informal sector, and making changes to the Tender Law. The Prime Minister has directed the Minister of Finance to develop additional venture capital opportunities for SMEs. Moreover, based on the project's work, a coherent new vision for SME development has been endorsed and adopted- Enhancing Competitiveness of Small and Medium Enterprises in Egypt: General Framework and Action Plan.

European Union: The European Union and the European Bank for Reconstruction and Development have also stepped up their support for SMEs in Egypt. The Small Business Support Program has already begun more than 100 projects to help Egyptian businesses access high-quality business advice, with the European Union providing $€ 2.4$ million to the program. As SMEs continue to suffer from poor access to finance, limited managerial skills and low productivity - greatly hampering their potential to create jobs - strengthening this area is a top priority for both the European Union and the European Bank for Reconstruction and Development in Egypt. The Small Business Support Program connects SMEs with the expertise that can transform their businesses. Working with local consultants and international experts, the program gives these businesses the tools, skills and know-how to innovate, attract finance and expertise, and become the next generation of business leaders. In addition to working with individual businesses, the European Bank for Reconstruction and Development also engages in policy dialogue with government agencies, local business associations and chambers of commerce to help promote the role of investment and local consultancy services in small-business development. To date, the multilateral development bank has invested approximately $€ 240$ million through 10 projects in Egypt, in various sectors, and has carried out more than 100 advisory projects with SMEs. [13]

Local and International Nongovernmental Organizations: Most nongovernmental organizations focus primarily on managing microcredits. The Aga Khan Foundation has implemented several socio- economic programs in Egypt in the Darb al-Ahmar district that are focused on housing rehabilitation, microfinance, apprenticeships and health care. Nurse's training and early childhood education programs are also underway in Aswan. The First Microfinance Foundation of Egypt was founded by the Aga Khan Agency for Microfinance, which is committed to alleviating poverty by boosting socio- economic development within low-income communities. They also provide access to financial and nonfinancial products and services in rural and urban areas.

\subsection{Private-Sector Initiatives to Promote the Micro, Small and Medium Enterprise Ecosystem}

Aside from mainstream reforms to improve credit information, creditor rights, and dispute resolution, MSMEs and startups in Egypt benefit also from other innovative financing such as angel finance, seed finance, venture capital and crowdfunding. Donors also had a stake in promoting MSME development. They contributed greatly to improving the business environment for MSMEs by easing access to finance, building the capacities of financial institutions, and offering business development services and training to service facilitators and providers.

The private sector has also stepped in to fill in the financing gap for startups. Many of the existing Egyptian entrepreneurship programs have strengthened and expanded alongside other donors' efforts in that regard, mainly in the last three years.

On the microfinance side, the efforts to develop MSMES have been minimal - the microfinance sector remains broadly underdeveloped, with microenterprises largely unable to obtain adequate finance.

From a policy implication standpoint — post January 25 and June 30 revolutions - there is a need for strategic economic reforms to vitalize Egypt's struggling economy and promote investment, especially for SMEs. This goal can be achieved through the following actions:

- Improving the legislative infrastructure, several bankruptcy rules and regulations, and creditor capacity to take fast possession of collateral in case of default; speeding up the process of establishing collateral registries, which should aim at building electronic registers and streamlining the registration process;

- Encouraging banks to build on their expertise in matchmaking their clients in different stages of the value chain (linkages);

- Updating financial methods for financial reporting (e.g., standardized template);

- Changing the entrepreneurial mindset; and

- Enhancing entrepreneurship education. [13]

The Government of Egypt should prioritize SME encouragement as part of its short- and long-term strategies for development. Procedures should be facilitated by allowing temporary licenses to be transformed into permanent licenses by the power of law within thirty days and by offering tax exemptions to SMEs for five years from the date of establishment.

Moreover, the institutional setting of MSME policy should be reconfigured: a single inter-ministerial body should oversee and coordinate the work of ministries, while a one-stop-shop arrangement for assisting and informing SMEs should be rolled out across Egypt's regions. The SME sector, dominated by informal businesses, needs formalizing: A Ministry of Finance task force should take a comprehensive, carefully coordinated approach towards the informal sector, one that combines incentives and encourages formality, growth and innovation.

Egypt should also provide better services and financial support to innovative SMEs by establishing linkages, 
promoting synergies between different support programs, and developing alternative financing, guarantee schemes, and research and development funds. Comprehensive packages of technical assistance, advisory services, and policy support are urgently needed to respond to the increasing demand for generating job opportunities and attaining a level playing field in the context of the Arab Spring upheavals.

\section{Overview of the Current Entrepreneurship Ecosystem in Egypt}

A strong, sound and synergetic entrepreneurship ecosystem is essential to start a grassroots entrepreneurial movement in Egypt and to show the economic impact out of all the entrepreneurship activities taking place. The Egyptian ecosystem has shown much progress since 2011, driven by a small group of successful businessmen deploying their own resources to develop a successful entrepreneurship ecosystem.

One of the major changes occurring in Egypt's entrepreneurship ecosystem over the last four years is the change in professional leadership of various entrepreneurship organizations. Several smart entrepreneurship organizations learned that they need to find passionate managers who are professional and transparent in their approach. This awareness is apparent among several organizations, including Flat 6 Labs, Endeavor, Middle East Council for Small Business and Entrepreneurship, and Nile University. [14] We have witnessed two major international nongovernmental organizations, Endeavor and Injaz, continue improving their programs as well. With the rise of these catalysts and leaders, some traditional business associations and government agencies have pulled back on their support to entrepreneurship, whereas others have tried to catch the rising stars. These polar tendencies are due largely to the political instability and the resulting difficult business environment. Prior to 2011, the typical entrepreneurship event in Egypt was a business plan competition hosted by a local business association and partially financed by the government, which did not create or support many businesses. [14] Today new generations of Egyptian ecosystem players are changing the formula; they are self-financing or receiving financing from the private sector. They rely on a multiple set of services-including mentoring, shared workspace and training-and have expanded their targets from just students. More recently, many organizations are shifting away from supporting entrepreneurs in the technology sectors to supporting entrepreneurs in other growth sectors, including waste removal and alternative energy.

In 2013, over 30 organizations that support entrepreneurs in Egypt have been identified - and the list continues to grow. The list includes nongovernmental organizations, universities, private-sector accelerators/incubators, companies, business associations and government agencies.

Although the number of entrepreneurship actors has grown, it is noticeable that not all organizations are making the same impact. What has become apparent over the last four years is that organizational and governance structures are keys to the success of any entrepreneurship program. In addition to the infrastructure, other factors such as culture, education and training, access to markets, funding and finance, skilled workforce and strong teams, and regulatory frameworks are strengthening the whole entrepreneurship ecosystem.

According to the World Economic Forum in 2012, the entrepreneurial ecosystem includes several components that affect the whole process, as represented in Figure 4 below.

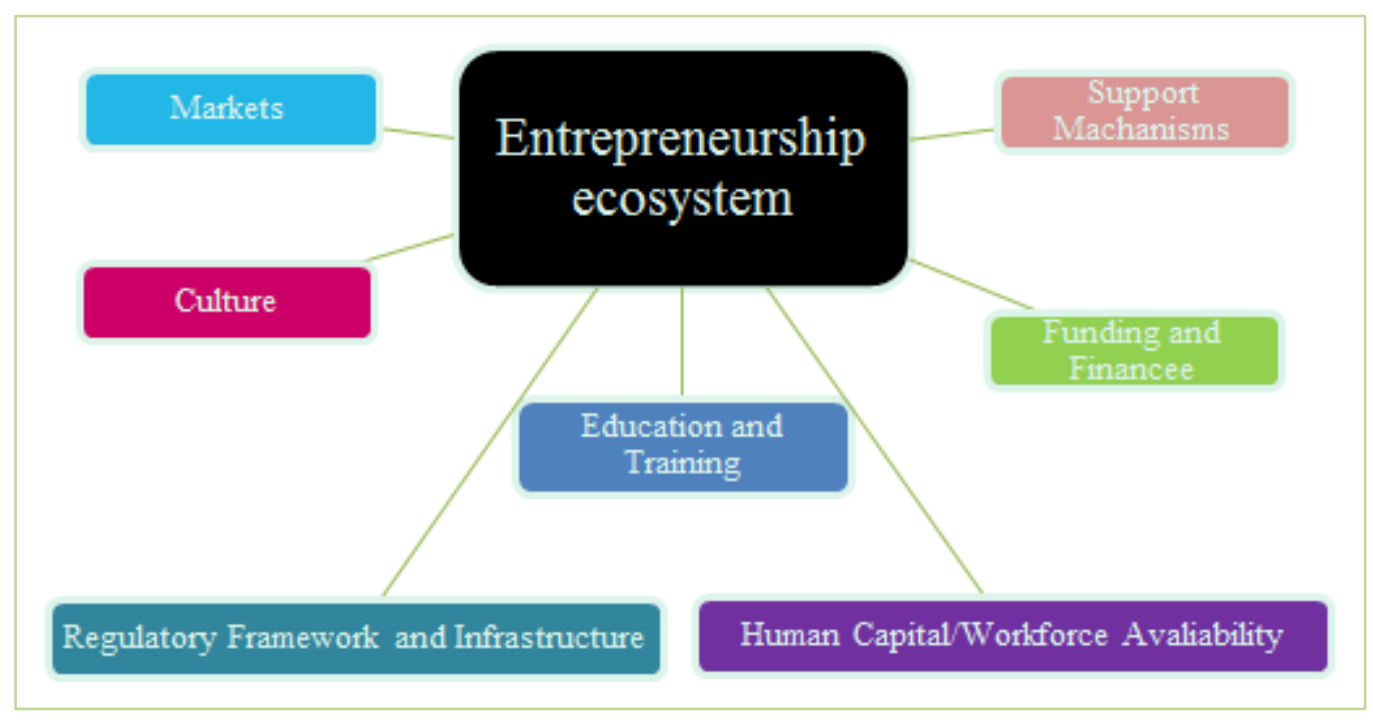

Figure 4. The Entrepreneurship Ecosystem [13] 
As outlined in Figure 4, there are six main components needed for creating an effective entrepreneurial ecosystem: markets, culture, education and training, funding and finance, human and workforce availability, and regulatory framework and infrastructure.

Accessible markets: The presence of accessible markets is one of the main pillars for establishing an entrepreneurial ecosystem in the region-but Egypt has been slow to capitalize on these opportunities. The major problem in accessing markets in Egypt is structural. According to the Doing Business Report in 2013, Egypt is considered one of the weakest countries in the world in enforcing contracts, ranking 152 out of 184 countries. In Egypt, companies are built based on personal relationships rather than enforceable legal contracts, which inevitably limit the amount of new business opportunities that can enter the market. Another obstacle is the major disconnect between supply and demand. Products are developed-not based on actual customers' needs - but rather on the contingency that they might create the need, leading to a great discrepancy.

Culture really matters: Entrepreneurial activities are highly manipulated by the cultural environment of the region. Before 2010, changing the mindset was considered a critical challenge, but progress has been made-attributable mainly to the media and social media that covered hundreds of inspirational stories about entrepreneurship. According to the Global Entrepreneurship Monitor Report, more individuals than previously find entrepreneurship to be a good career choice, have less fear of failing as an entrepreneur, and see more opportunities to become entrepreneurs.

Education and training: Since 2011, Egypt has placed great emphasis on providing programs on entrepreneurship to secondary schools and universities, which has continued to increase, but with diversification towards technology. According to the General Authority for Investment and Free Zones, the information communication and technology sector accounted for $4.28 \%$ of social entrepreneurship and GDP in 2011 , which grew at a rate of over $11.5 \%$ between 2011 and 2012. [15]

Raising funds and access to finance: Before 2011, entrepreneurs had been depending on the banks, families and friends to finance their projects. In 2010, entrepreneurs faced difficulties in getting commercial loans due to the high risks associated with their projects. However, in the last four years, other forms of funding such as angel investments, crowdfunding, venture capitals and private equity have performed strongly.

Human and workforce availability: One of the most important components for any successful entrepreneur is their initial workforce. Egypt lacks skilled labor, which is a primary obstacle to upgrading growth companies. In 2010, Egypt ranked last compared to other countries in the level and quality of education of primary and secondary schools on encouraging creativity, self-sufficiency and personal initiative.

Regulatory framework and infrastructure: In terms of government policies, Egyptian entrepreneurs still face several obstacles related to bureaucracy, taxes being imposed on new and growing firms, and in obtaining required permits and licenses. Thus, most early-stage businesses tend to be informal. The Ease of Doing Business Index for 2012 shows that rates for starting a business in Egypt has receded, especially in terms of paying taxes and dealing with permits.

\subsection{Egyptian Entrepreneurship Ecosystem: Strengths, Weaknesses, Opportunities and Threats Analysis}

In Egypt, it is rare to find entrepreneurs who are taking advantages of change to create innovative, valuable products or business models that will lead Egypt into new growth markets. Most Egyptian entrepreneurs show little desire to grow and thus are not pursuing new markets or products. There is no concrete data that explains this lack of desire to grow, but the entrepreneurial mindset may be a part of the cause (as discussed previously in the chapter).

Still, there are some exciting areas of innovation and entrepreneurship in Egypt - in particular, the information and communications technology sector-that have a promising number of growth entrepreneurs. In other sectors, such as food processing and textiles, the majority of Egyptian entrepreneurs are simply duplicating other pre-existing businesses run by family members, friends or neighbors. These duplicating entrepreneurs reduce risk via letting others test markets, products and business models. This form of entrepreneurship does not contribute much additional value to the economy, especially unfortunate given there are so few innovations being introduced in Egypt. This type of entrepreneurship is one possible reason for the interest in franchising among investors like the Social Fund for Development. Egyptian financial organizations prefer franchising because it provides an easily understood, live financial model that has been tested. [16]

Meanwhile, there are many entrepreneurship initiatives that have been implemented recently. Several gaps still exist, however, in the system. Two critical gaps are commercial opportunity recognition and private- sector collaboration. As stated previously, it is critical for entrepreneurs to be able to identify and react to change by creating new products, business models or processes. Entrepreneurs also need to recognize that change will most often occur in the market place. This means entrepreneurs need to engage with market players and test new ideas. They need to understand how to investigate the unknown-namely, how to capture opportunities about markets when there is no existing market analysis. To do so, entrepreneurs must cooperate with market players to identify problems and opportunities. The table 1 shows the strengths, weaknesses, opportunities and threats of the Egyptian ecosystem in light of what was mentioned above. 
Table 1. Egyptian Entrepreneurship Ecosystem - SWOT Analysis

\begin{tabular}{|c|c|}
\hline Strengths & Opportunities \\
\hline $\begin{array}{l}\text { Egypt's unique geographical location in the center of the world } \\
\text { Large and young population with multilingual capabilities } \\
\text { Existence of local initiatives that support Egyptian entrepreneurs } \\
\text { Existence of incubators and accelerators } \\
\text { More comprehensive training programs provided to entrepreneurs } \\
\text { New entrepreneurship media }\end{array}$ & $\begin{array}{l}\text { Increased desire from multinationals to support entrepreneurs in } \\
\text { innovation } \\
\text { An increasing number of public-private partnerships in Egypt after the } \\
2011 \text { revolution } \\
\text { Other means of funding such as crowdfunding, angel investments and } \\
\text { private equity } \\
\text { Different initiative setup - such as accelerators, incubators, co-working } \\
\text { spaces, angel groups, crowdfunding platforms, venture funds and startup } \\
\text { training } \\
\text { The growth of startup competitions } \\
\text { A change in the entrepreneurial mindset } \\
\text { New models recently developed whereby nongovernmental } \\
\text { organizations, universities, private-sector incubators and accelerators, } \\
\text { government agencies, and mentors collaborate to implement } \\
\text { cost-effective entrepreneurship initiatives }\end{array}$ \\
\hline Weaknesses & Threats \\
\hline $\begin{array}{l}\text { Insufficient number of qualified graduates } \\
\text { Low quality of education regarding innovation, creativity, leadership } \\
\text { skills and management } \\
\text { Immigration of talented Egyptian entrepreneurs Political instability } \\
\text { Lack of talented and trained employees } \\
\text { Centralization of services promoting entrepreneurs } \\
\text { Absence of coherent network of entrepreneurs } \\
\text { Access to land }\end{array}$ & $\begin{array}{l}\text { Harsh competition (internally and externally) } \\
\text { High - speed of technology development that will be difficult for some } \\
\text { entrepreneurs to cope with } \\
\text { Bureaucracy } \\
\text { Restricted policies and regulations, especially for taxes and licensing }\end{array}$ \\
\hline
\end{tabular}

Over the last four years, the Egyptian entrepreneurship ecosystem has kept a watchful eye on the future orientation of enterprise growth; the international, regional and local media have also covered the incredible changes. Young Egyptians want to be entrepreneurs, and now many more than before show respect to others who have chosen to take this path. There has been an implausible growth in entrepreneurship programs and events over the last four years and in the number of organizations and people providing early-stage technical support and financing to entrepreneurs. Many of the existing Egyptian entrepreneurship programs have strengthened and expanded in tandem with other donors' efforts in that regard. Yet, progress is mostly due to a select number of Egyptian private-sector individuals who have made a concentrated effort to make a difference. These individuals include Ahmed El-Alfi and Hany Sonbaty, founders of Flat 6 Labs and Sawari Capital; Dr. Khaled Ismali, Chairman of Endeavor and founder of KiAngles; Ihab El-Fouly and Tarek Fahim of Tamkeen Capital; Hossam Allam and Con O'Donnell from Cairo Angels; Mohammed Gawdat and Samer ElSahn from Tahrir Square; and Shereen Allam of
AWTAD, which supports women entrepreneurs. These individuals contributed considerable financial resources - and time - to change the ecosystem in Egypt. [17]

\section{Example of the innovation Eco system of company in Egypt}

IBM is providing cloud computing expertise to one hundred Egyptian Software Companies to help drive innovation and new cloud development skills. This is part of a collaborative agreement with the Egyptian Information Technology Industry Development Agency (ITIDA), in which IBM will offer its expertise to the ISVs with the aim of boosting Egypt's efforts to become a center of cloud computing excellence in the region.

While current spending on public cloud services in the country is lower than its regional peers, Egypt represents the fastest growing market across the Middle East and Africa, with $67 \%$ growth expected for 2014 alone, according to IDC (see fig. 5). 


\title{
Cloud's Silver Lining Forecast for Africa
}

\begin{abstract}
With 9 in every 10 African IT leaders listing cloud as critical to business success*, governments and companies across the continent are already identifying innovative ways to leverage the technology - leapfrogging regional challenges and eyeing new solutions to export to developed markets.
\end{abstract}

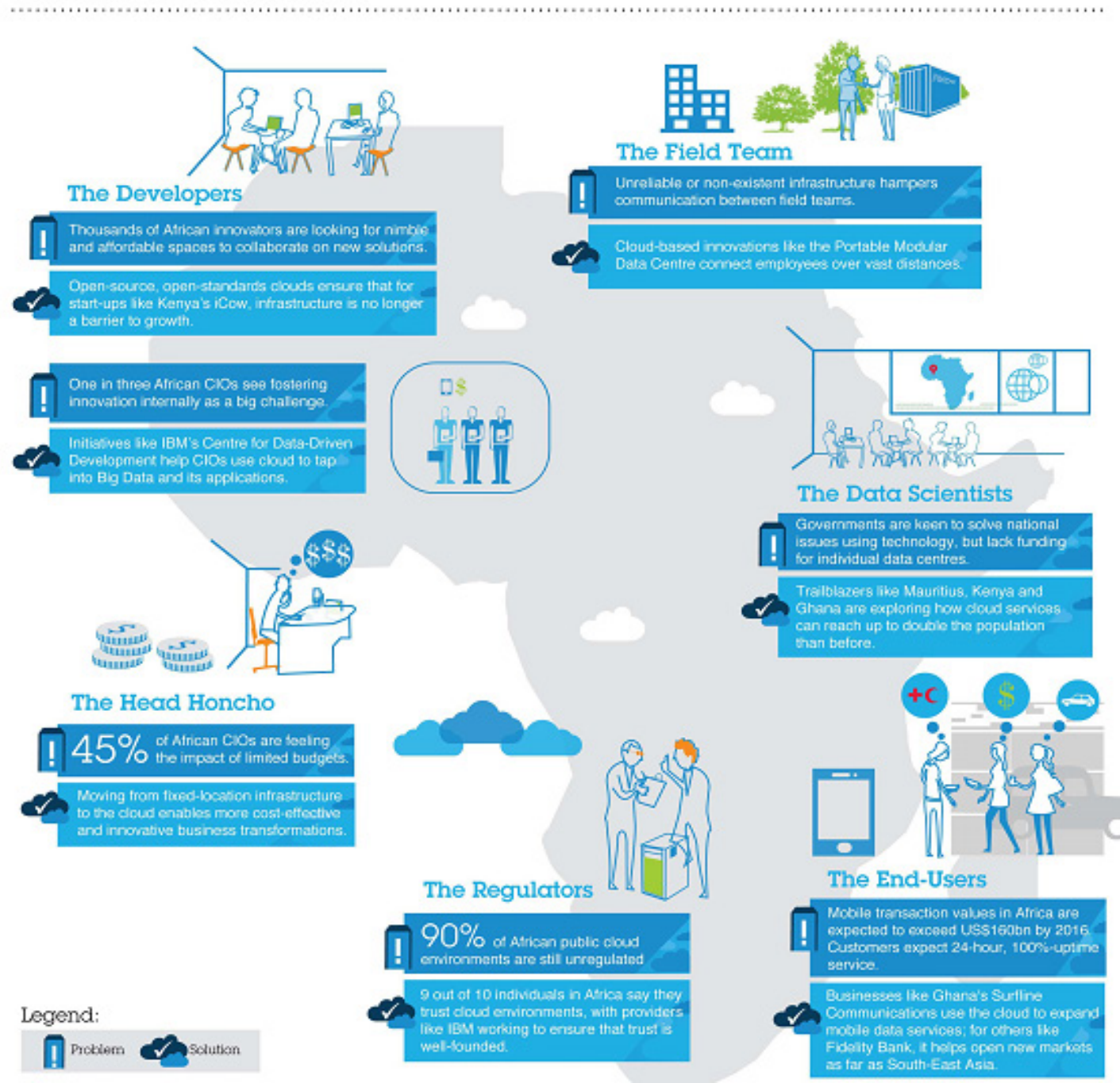

Figure 5. Cloud silver forecast ecosystem of IBM for Africa

The agreement is in line with ITIDA's strategy to provide support for small and medium IT companies to be able to expand their offerings to new markets and help grow the Egyptian economy based on the proliferation of technology trends such as big data. As data is the life blood of every organization, businesses are challenged with using it to gain insights and transform with speed. IBM Cloud is enabling clients to harness all available data and apply the full power of analytics on a massive scale, privately and securely.

The first 20 companies to benefit from this collaboration were announced at a ceremony in Cairo today. IBM Cloud-enabled access will help these companies develop their information technology solutions by enabling the creation and testing of cloud solutions in a faster and more cost-effective way. The ISVs will provide their solutions on the cloud, reaching a wider audience of clients and users with minimal capital expenditure. ITIDA will choose the remaining ISVs in groups of twenty, every three months.

As part of the agreement, IBM will also educate and train the participating Software developers on how to develop and port their solutions to different IBM cloud computing platforms such as Softlayer infrastructure and Bluemix. Bluemix is IBM's unique development environment built on SoftLayer to help developers quickly integrate applications 
and speed deployment of new cloud services, learn new development skills, and access IBM's developer ecosystem to drive cloud innovation. Using an open cloud environment, Bluemix helps both born-on-the-web and enterprise developers build applications with their choice of tools.

With the ability to easily combine a variety of services and APIs from across the industry to compose, test and scale custom applications, developers will be able to cut deployment time from months to minutes.

New applications and cloud services ISVs developed on Bluemix can give Egyptian ISVs the opportunity to expand their business globally by offering their innovations on the IBM Cloud Marketplace, an enterprise single online destination for IBM-as-a-service and its cloud ecosystem. "The IBM initiative is an important step towards stimulating the growth of cloud computing applications, expertise, knowhow, promoting the culture, and use of "Applications as a Service (AAS)" in the market, particularly in the Middle East and Africa," said Hussein El Gereitly, CEO of ITIDA.

As part of the agreement, IBM will help deepen the technical and business expertise of the ISVs through a series of workshops and mentoring.

"This project is part of our ongoing commitment to the local market. It will enable these companies to grow without large capital costs. This is a real bonus for Egypt's fast-growing entrepreneurial clusters, which often lack funding or physical IT infrastructure," said Amr Talaat, Country General Manager, IBM Egypt.

These programs are examples of a set of investments that IBM is making to support IT skills development in Africa. Earlier this year, IBM announced several IT knowledge-building initiatives across the continent to enable the existing and future workforce to develop new analytics, cloud and data skills crucial to the continent's economic growth and social development.

IBM also announced a $\$ 100$ million investment to bring Watson and other cognitive systems to Africa to fuel development across the continent in an ambitious 10 year project.

In 2013, the company opened the doors of its first African Research Laboratory, which is conducting research into the grand challenges of the African continent, drawing insight from vast amounts of data to find solutions to Africa's most pressing challenges such as energy, water, transportation, agriculture and healthcare. [18]

\section{Conclusions}

Developing countries usually perceive MSMEs as a dynamic force for sustained economic growth and job creation. In Egypt-despite institutional, regulatory, and banking efforts and reforms by the government, donors, and private sector - the ability of MSMEs to expand, grow and sustain their activities is still held back by numerous challenges. These enterprises are geographically concentrated in one or two governorates, operating chiefly in two economic activities - manufacturing and trade. The major challenges faced in these sectors are non-conducive legal, regulatory and supervisory frameworks.

The easy access to suitable and sufficient means of finance has always been considered a major obstacle faced in many MSMEs. After the revolution, it has become even more difficult for any such enterprise to obtain commercial lending as banks have been financing the growing demands of the government debt. Financial services seem to be underutilized by these businesses as only $50 \%$ are dealing with banks and benefiting from an improved access to finance. On one side, banks cite a lack of enterprise transparency, difficulties in using collateral, and uncertainty over creditor rights as primary barriers to their greater involvement in finance. There are also high administrative costs of small-scale lending, as well as inadequate banking skills for dealing with MSMEs where there is need to build the capacity of financial intermediaries, especially banks (and mainly state-owned banks). On the other side, MSMEs' limited access to finance can be attributed to their incapacity to prepare business plans and loan applications, as well as their tendency to have opaque or nonexistent financial statements and insufficient collateral.

Aware of the importance of developing and promoting MSMEs, the Government of Egypt has undertaken several initiatives to support this end, either on the policy or the regulatory level. Yet, neither a national strategy or policy — nor a comprehensive package of policies—has been formulated. The MSME ecosystem in Egypt needs to be aided by its government, not only through debt support, but also through policy and infrastructure support like collateral registry and a microfinance law.

Growth-focused entrepreneurs are major job creators. In many ways the 2011 revolution has marked the beginning of a new Egyptian entrepreneurship ecosystem that now focuses on growth entrepreneurs driven more by effective stakeholders than by government agencies or traditional business associations. These stakeholders include a small group of individuals from the private sector who have stepped in and spearheaded an entrepreneurship development movement in the country. These individuals have set up accelerators, incubators, co-working spaces, angel groups, crowdfunding platforms, venture capital funds and startup training initiatives. Egypt has also seen in the last four years passionate and professional managers from various entrepreneurship NGOs and private universities assume leadership roles to help accelerate their programs. Despite some universities being hindered by their governance structures in their ability to support young entrepreneurs, most still manage to drive their initiatives with the support of student groups. The majority of these initiatives are also supported by hundreds of new private-sector volunteers who mentor, guide, advise, and teach - and sometimes invest as an angel investor. Due to the growth of the Egyptian ecosystem and support from different donors, there is now a greater positive perception of 
entrepreneurship in Egypt. These initiatives have established Egypt as one of the major entrepreneurship hubs in the Middle East and North Africa region, a distinction which has been highlighted in the international press. While these private-sector leaders, nongovernmental organizations and youth groups led the new wave of entrepreneurship activities in the ecosystem, traditional players have played a much smaller role. Government agencies and traditional business associations that drove the entrepreneurship activities before 2010 have been hampered by the political instability of the last three-and-a half years, a constraint that has led to new models being developed whereby nongovernmental organizations, universities, private-sector incubators/accelerators, government agencies and mentors collaborate to implement cost-effective entrepreneurship initiatives.

While the growth of these new initiatives during a politically unstable time is inspiring, many new initiatives are still narrowly focusing on startups, technology and social entrepreneurship. There is not much support for pure growth-focused, non- technology and nonsocial entrepreneurs.

Entrepreneurs are also facing many constraints, such as finding the appropriate sources of finance and the right talent or product/market to grow their company. The entrepreneurial culture is nonexistent and Egypt's education system ranks among the poorest in the world-two major impediments that reduce the potential to start, to expand or grow a business. Entrepreneurs have limited access to many of the markets controlled by stated- owned entities, government joint ventures or large corporations that tend not to outsource. Early-stage entrepreneurs struggle to get access to land and support services due to layers of bureaucracy and a lack of voice to advocate for a better business environment. The ecosystem emerged with a bang, but it's only the beginning of a long and difficult journey.

\section{REFERENCES}

[1] Central Agency for Public Mobilization and Statistics

[2] The Roadmap is for a transfer to civilian power and includes the successful completion of parliamentary elections.

[3] According to the data of the Central Agency for Public Mobilization and Statistics (CAPMAS), the monthly Consumer Price Index (CPI) inflation remained constant at 0.9\% from June 2013 to June 2014."

[4] According to the most recent labor force sample survey conducted at the end of Q1 FY14, the unemployment rate stood at $13.4 \%$ compared to $13.2 \%$ at the end of Q1 FY13.

[5] Egypt statistical data web page, URL: http://www.geohive.com/cntry/egypt.aspx

[6] Doing Business Subnational (World Bank and International
Finance Corporation), Doing Business in Egypt Report 2014.

[7] MENA is the Middle East and North Africa regional average. Egypt and other economies are represented by their largest business city ranking are based on doing Business 2014: understanding regulations for small-medium size enterprises. Source: Doing Business database

[8] Creative Associates International, Special Focus on Entrepreneurship, Streamlining Business Procedures and Value Chain Analysis, Aug. 2014, URL: http://www.creativeassociatesinternational.com/wp-content/u ploads/2003/01/Micro_Small_and-_Medium_Enterprises_in Egypt.pdf

[9] Egypt's Innovation Ecosystem, Innovation Support Department - Science \& Technology Development Fund Cairo, Egypt, URL:http:/www.stdf.org.eg/files/Egypt\%20In novation $\% 20$ Ecosystem.pdf

[10] Sahar Nasr Nahla Elokda, Efforts to Support Micro and Small Enterprises, CGAP, URL:http://www.cgap.org/blog/efforts-s upport-micro-and-small-enterprises

[11] Mahmoud Al-Said, Hala El-Said, Chahir Zaki, Small and Medium Enterprises Landscape in Egypt: New Facts from a New Dataset, URL: http://www.sme-egypt.com/Documents/ A\%20paper\%20on\%20SMEs\%20Landscape\%20in\%20Egyp t.pdf

[12] World Bank (2013) From Privilege to Competition: Unlocking Private-Led Growth in the Middle East and North Africa, Washington DC: The International Bank for Reconstruction and Development / The World Bank, p. 26, URL:http://www.cipe-arabia.org/index.php/around-the-worl $\mathrm{d} /$ tunisia/1225-understanding-entreperneurship-ecosystem-in -tunisia-egypt

[13] Creative Associates International, Special Focus on Entrepreneurship, Streamlining Business Procedures and Value Chain Analysis, Aug.2014, URL: http://www.creativeassociatesinternational.com/wp-content/u ploads/2003/01/Micro_Small_and-_Medium_Enterprises_in _Egypt.pdf

[14] Amr Adly, Understanding the Entrepreneurship Ecosystem in Tunisia and Egypt, CENTER FOR INTERNATIONAL PRIVATE ENTERPRISE, December 16, 2013, URL: http://www.cipe.org/publications/detail/understanding-entrep reneurship-ecosystem-tunisia-and-egypt

[15] A Social entrepreneur is an individual with innovative solutions to society's most pressing social problems. He/she is ambitious and persistent, tackling major social issues and offering new ideas for wide-scale change, URL: www.ashoka.org

[16] Egypt entrepreneurship report, URL: http://www.academia.ed u/5193052/EGYPT ENTREPRENEURSHIP FINAL REP ORT_WHERE_ARE_ALL_THE_EGYPTIAN̄ ENTREPRE NEURS

[17] United States Agency for International Development, "Egypt Entrepreneurship: Success, Challenges and the Lessons of Supporting Job- Generating Entrepreneurs in Egypt," Cairo, 2013.

[18] IBM official web page, URL: https://www-03.ibm.com/press/ us/en/pressrelease/44158.wss. 